\title{
Reliability of Abnormal $Q$ and QS Patterns Classified by the Minnesota Code for the Diagnosis of Myocardial Infarction in Aged People
}

\author{
Hiroshi Kurihara, M.D., Kizuku Kuramoto, M.D., Fujio \\ Terasawa, M.D., Satoru Matsushita, M.D., Masuji \\ Seki, M.D.* and Masao IkedA, M.D.
}

The reliability of the $Q$ and $Q S$ patterns classified by the Minnesota code for the diagnosis of myocardial infarction was studied in 697 consecutive autopsied cases including 82 cases of myocardial infarction. Abnormal $Q$ and $Q S$ patterns were observed in 111 of 615 non-infarction cases, while 42 of 82 cases with myocardial infarction showed these patterns. The persistent appearance of the I-1 $Q$ waves was highly reliable for the diagnosis of myocardial infarction, while the transient or terminal appearance of the I-1 $Q$ waves revealed low reliability. The I-2 and the I-3 $Q$ waves revealed little reliability regardless of the type of their appearance.

\begin{abstract}
A
BNORMAL $Q$ and QS patterns have been recognized as one of the most have previously reported ${ }^{11}$ the incidence of the $Q$ and QS patterns classified with the Minnesota code ${ }^{2,3)}$ on autopsy proven myocardial infarction in the aged. However, it is well known that such Q and QS patterns are also found in cases without myocardial infarction." ${ }^{4}$ The purpose of the present paper is to evaluate the reliability of the classified $Q$ and QS patterns for the diagnosis of myocardial infarction in consecutively autopsied cases of the aged.
\end{abstract}

\section{Materials AND Methods}

All available electrocardiograms of 697 cases of consecutive autopsies over the age of 60 at Yokufukai Geriatric Hospital, from October 1958 through February 1966, including 82 cases of myocardial infarction, were reviewed with respect to the $Q$ and $Q S$ patterns classified by the Minnesota code. In this study, the additional items of the QS patterns in leads II, III and $\mathrm{aV}_{\mathrm{F}}$, which were not employed in the original code, were also reviewed. Almost every patient had serial electrocardiograms recorded more frequently than every half year, and the percentage

From the Third Department of Internal Medicine (Director: Prof. Kiku Nakao, M.D.), Faculty of Medicine, University of Tokyo, Tokyo.

* Yokufukai Geriatric Hospital (Director: Fujiro Amako, M.D.), Tokyo.

Received for publication October 31, 1966. 
Table I. The Distribution of Sex and Age of the Subjects

\begin{tabular}{c|c|c|c|c}
\hline Sex Age yr. & $60-69$ & $70-79$ & $80-$ & Total \\
\hline Male & 36 & 130 & 69 & 235 \\
\hline Female & 51 & 218 & 193 & 462 \\
\hline & 87 & 348 & 262 & 697
\end{tabular}

of autopsy of the deceased patients at this hopsital during the above periods was about 99 per cent. The distribution of the sex and the age of the cases is presented in Table I. One hundred forty-three cases had tracings showing $Q$ or $Q S$ patterns meeting the criteria of each item of class I-1, -2 and -3 , and the reliability of these $Q$ or QS patterns for the diagnosis of myocardial infarction was analysed. The postmortem examination of the heart was done macroscopically after formalin fixation and myocardial ischemic lesions exceeded $2 \mathrm{~cm}$. in 1 diameter were defined as myocardial infarcts.

The most abnormal changes in the serial electrocardiograms were employed for the analysis. The $Q$ and $Q S$ patterns in the serial tracings were divided into four groups by the type of appearance. 1) the persistent type, which persists for long duration, 2) the transient type, which is observed transiently and disappears in the following records, 3) the terminal type, which appears at the terminal stage, and 4) the undetermined type, which appears in a tracing taken half a year or more prior to death and after which no tracings were taken.

As for the $Q$ and QS sub-items, the most abnormal changes in each of them in the serial electrocardiograms were employed independently. Among the group of leads I, II, $\mathrm{V}_{2}-\mathrm{V}_{6}$, Q patterns were classified according to the criteria as shown in Table II.

Table II. Criteria for the $Q$ Wave in Leads of I, II, $V_{2}-V_{6}$

\begin{tabular}{c|c|c|c}
\hline R-duration sec. & $\geqq 1 / 3$ & $1 / 3>\geqq 1 / 5$ & $1 / 5>$ \\
\hline$\geqq 0.04$ & $\mathrm{I}-1-\mathrm{a}^{*}$ & $\mathrm{I}-\mathrm{I}-\mathrm{b}^{*}$ & $\mathrm{I}-1-\mathrm{b}^{*}$ \\
\hline $0.04>\geqq 0.03$ & $\mathrm{I}-1-\mathrm{a}$ & $\mathrm{I}-2-\mathrm{a}$ & $\mathrm{I}-2-\mathrm{b}$ \\
\hline $0.03>$ & $\mathrm{I}-3-\mathrm{a}$ & $\mathrm{I}-3-\mathrm{c}$ & $\mathrm{I}-0$
\end{tabular}

* $Q$ wave in lead $V_{1}$ with its duration more than 0.04 sec. is counted into the item of $1-1-b$.

\section{Results}

I) Incidence of the classified $Q$ and $Q S$ patterns in the aged

Table III shows the incidence of the classified $Q$ and QS patterns in the present series. Among all 697 cases, all abnormal $Q$ and QS patterns meeting the criteria of the I-1, -2 , and -3 classifications were observed in 143 cases or 
Table III. Incidence of the Glassified $Q$ and QS Patterns in the Present Subjects

\begin{tabular}{|c|c|c|c|c|c|}
\hline & $\begin{array}{c}\text { Total No. of } \\
\text { Cases }\end{array}$ & I-1 & I-2 & I -3 & $\begin{array}{l}\text { Total Abnormal } \\
Q \text { or QS Patterns }\end{array}$ \\
\hline Total & 697 & 71 & $\begin{array}{l}49 \\
(7.0 \%)\end{array}$ & $\begin{array}{l}23 \\
(3.3 \%)\end{array}$ & $\begin{array}{l}143 \\
(20.5 \%)\end{array}$ \\
\hline $\begin{array}{l}\text { Non-myccard. } \\
\text { Infacts }\end{array}$ & 615 & ${ }^{39}(6.3 \%)$ & ${ }^{42}(6.8 \%)$ & $\begin{array}{l}20 \\
(3.3 \%)\end{array}$ & ${ }_{(16.4 \%)}^{101}$ \\
\hline \multirow{2}{*}{$\begin{array}{l}\text { Myocardial } \\
\text { Infacts }\end{array}$} & 82 & 32 & $\begin{array}{l}7 \\
(8.5 \%)\end{array}$ & $\begin{array}{l}3 \\
(3.7 \%)\end{array}$ & $\begin{array}{l}42 \\
(51.5 \%)\end{array}$ \\
\hline & $65 *$ & $(49 \%)$ & $(11 \%)$ & $(4.6 \%)$ & $(64.6 \%)$ \\
\hline
\end{tabular}

* After excluding 17 cases without any reportable Q or QS patterns, because of the lack of a tracing within one month of death or after the onset of infarction.

$20.5 \%$, including 24 cases of myocardial infarction. Among the 615 cases without myocardial infarction, 101 cases or $16.4 \%$ had tracings with the abnormal $Q$ and QS patterns. The incidence of the I-1, I-2, and I-3 was 39 cases or $6.3 \%, 42$ cases or $6.8 \%$, and 20 cases or $3.3 \%$, respectively. Among 82 cases with myocardial infarction, the classified $Q$ and $Q S$ patterns were observed in 42 cases or $51.2 \%$. If we exclude 17 cases without any reportable $Q$ and QS patterns because of the lack of a tracing taken within one month of death or after the onset of infarction, 42 of 65 cases or $64.6 \%$ of the cases of myocardial infarction showed the abnormal $Q$ and QS patterns, in which a high prevalence of I-1 was observed.

Among 39 cases of the I-1 classification in the non-infarcted cases, the transient type and the terminal type were observed in 14 cases and 16 cases, respectively. Among 32 cases of the I-1 in the infarcted cases, on the other hand, 17 cases showed persistent $Q$ waves. Differences in the type of appearance of I-2 and I-3 were not observed between the non-infarcted and the infarcted cases. Five cases with the $\mathrm{QS}$ pattern in leads II, III or $\mathrm{aV}_{\mathrm{F}}$ were seen in the non-infarcted cases and 6 in the infarcted cases, in which 4 cases revealed the persistent type.

II) The incidence of myocardial infarction in the cases which showed the classified $Q$ and QS patterns (Table IV)

Among the total 143 cases with the abnormal $Q$ and QS patterns, 42 cases or $29.3 \%$ were proved myocardial infarction at autopsy. The incidence of myocardial infarction in the I-1, I-2, and I-3 was 32 of 71 cases or $45.0 \%$, 7 of 49 cases or $14.3 \%$ and 3 of 23 cases or $13.0 \%$, respectively. Among 26 cases with the persistent type of $\mathrm{I}-1$, myocardial infarction was found in 17 , or $65.4 \%$. In the transient type and the terminal type of I-1, the incidence of infarction was $39.1 \%$ and $20.0 \%$, respectively. Six of 9 cases with complete 
Table IV. Incidence of Myocardial Infarction in the Cases Which Showed the $Q$ and QS Patterns, Classified According to the Type of Appearance

\begin{tabular}{|c|c|c|c|c|c|c|c|}
\hline \multicolumn{4}{|c|}{ E.G.G. Findings } & \multicolumn{4}{|c|}{ Pathological Findings } \\
\hline \multirow{2}{*}{$\begin{array}{l}\text { Min- } \\
\text { nesota } \\
\text { Code }\end{array}$} & \multirow{2}{*}{$\begin{array}{c}\text { Type of } \\
\text { Appearance }\end{array}$} & \multirow{2}{*}{$\begin{array}{l}\text { No. of } \\
\text { Cases }\end{array}$} & \multirow[b]{2}{*}{ Total } & \multicolumn{2}{|c|}{ Myocardial Infarcts } & \multicolumn{2}{|c|}{ Non-myocard. Infarct } \\
\hline & & & & $\begin{array}{c}\text { No. }(\%) \text { of } \\
\text { Cases }\end{array}$ & Total & $\begin{array}{c}\text { No. of } \\
\text { Cases }\end{array}$ & Total \\
\hline \multirow[t]{4}{*}{ I-1 } & Persistent & $\begin{array}{r}26 \\
* 5 \\
* * 5\end{array}$ & \multirow{4}{*}{$\begin{array}{l}71 \\
* 9 \\
* * 11\end{array}$} & $\begin{array}{c}17(65.4 \%) \\
* 2 \\
* * 4\end{array}$ & \multirow{4}{*}{$\begin{array}{c}32(45.0 \%) \\
* 3 \\
* * 6\end{array}$} & $\begin{array}{r}9 \\
* 3 \\
* * 1\end{array}$ & \multirow{4}{*}{$\begin{array}{r}39 \\
* 6 \\
* * 5\end{array}$} \\
\hline & Transient & $\begin{array}{r}23 \\
* 4 \\
* * 4\end{array}$ & & $\begin{array}{c}9(39.1 \%) \\
* 1 \\
* 2\end{array}$ & & $\begin{array}{r}14 \\
* 3 \\
* * 2\end{array}$ & \\
\hline & Terminal & $20 * * 2$ & & $4(20.0 \%)$ & & ${ }^{16} * 2$ & \\
\hline & Undetermined & 2 & & 2 & & 0 & \\
\hline \multirow[t]{4}{*}{$1-2$} & Persistent & $15 * 1$ & \multirow{4}{*}{$49 * 4$} & $3(20.0 \%)$ & \multirow{4}{*}{$\begin{array}{c}7(14.3 \%) \\
* 1\end{array}$} & ${ }^{12} *_{1}$ & \multirow{4}{*}{$42 * 3$} \\
\hline & Transient & ${ }^{18} * 1$ & & $1(5.6 \%)$ & & $17 * 1$ & \\
\hline & Terminal & ${ }^{16} * 2$ & & $\begin{array}{c}3(18.8 \%) \\
* 1\end{array}$ & & $13 * 1$ & \\
\hline & Undetermined & 0 & & 0 & & 0 & \\
\hline \multirow[t]{4}{*}{ I-3 } & Persistent & 8 & \multirow{4}{*}{23} & $2(25.0 \%)$ & \multirow{4}{*}{$3(13.0 \%)$} & 6 & \multirow{4}{*}{20} \\
\hline & Transient & 8 & & $1(15.0 \%)$ & & 7 & \\
\hline & Terminal & 6 & & 0 & & 6 & \\
\hline & Undetermined & 1 & & 0 & & 1 & \\
\hline \multicolumn{2}{|c|}{$\begin{array}{l}\text { I-1, I-2 and I-3 } \\
\text { Total }\end{array}$} & & $\begin{array}{l}143 \\
* 13 \\
* * 11\end{array}$ & & $\begin{array}{c}42(29.3 \%) \\
* 4 \\
* * 6\end{array}$ & & $\begin{array}{r}111 * 9 \\
* * 5\end{array}$ \\
\hline I-0 & & & $\begin{array}{c}554 \\
* * * 244\end{array}$ & & $\begin{array}{c}40(6.8 \%) \\
* * * 23 \\
(9.4 \%)\end{array}$ & & $\begin{array}{l}514 \\
* * * 221\end{array}$ \\
\hline Total & & & 697 & & 82 & & 615 \\
\hline
\end{tabular}

right bundle branch block included in I-1 failed to prove myocardial infarction. A low incidence of myocardial infarction in the I-2 and I-3 classifications was seen regardless of the type of appearance.

Among 554 cases of I-0 showing no abnormal Q and QS patterns, 40 were proved at autopsy to have myocardial infarction. If 310 cases without a 
final tracing taken within one month of death are excluded, because the possibility of occurrence of infarction after taking a final record could not be denied, 23 of 244 cases or $9.4 \%$ were found to have myocardial infarction without any $Q$ and QS patterns until death.

III) Accuracy of each Q and QS sub-item for the diagnosis of myocardial infarction

Table V. Reliability of Each $Q$ and QS Sub-items for the Diagnosis of Myocardial Infarction

\begin{tabular}{|c|c|c|c|c|c|c|c|c|c|c|c|}
\hline \multirow{2}{*}{\multicolumn{2}{|c|}{$Q \underset{\text { Items }}{\text { and }} \mathrm{QS}$}} & \multirow{2}{*}{\multicolumn{2}{|c|}{$\begin{array}{l}\text { No. of Cases } \\
\text { Total (Infarct) }\end{array}$}} & \multicolumn{7}{|c|}{ Type of Appearance } & \\
\hline & & & & \multicolumn{2}{|c|}{ Persistent } & \multicolumn{2}{|c|}{ Transient } & \multicolumn{2}{|c|}{ Terminal } & $\begin{array}{c}\text { Un- } \\
\text { determined }\end{array}$ & \\
\hline \multirow[t]{10}{*}{$I-1$} & a & 23 & (14) & & (7) & 4 & (2) & & (4) & \multirow[t]{6}{*}{1 (1) } & \multirow{10}{*}{$\begin{array}{ll}\text { QS } & \text { II } \\
\text { QS } & \text { III } \\
\text { QS } & \text { aVE }\end{array}$} \\
\hline & $b$ & 13 & (1) & & $(0)$ & 5 & $(0)$ & 3 & (1) & & \\
\hline & c & 10 & (4) & & (3) & 2 & $(0)$ & 3 & (1) & & \\
\hline & $\mathrm{d}$ & 14 & (9) & 6 & (5) & 6 & (4) & 2 & (0) & & \\
\hline & $\mathrm{e}$ & 7 & (6) & 3 & (3) & 3 & (3) & 1 & (0) & & \\
\hline & f & 19 & (9) & 3 & (3) & 8 & (4) & 8 & (2) & & \\
\hline & $\mathrm{g}$ & 5 & (3) & 0 & & 0 & & 4 & (1) & \multirow[t]{4}{*}{1 (1) } & \\
\hline & $\mathrm{b}^{\prime}$ & 4 & (3) & 2 & (1) & 0 & & 2 & (2) & & \\
\hline & $d^{\prime}$ & 13 & (7) & 4 & (3) & 5 & (2) & 4 & (2) & & \\
\hline & $\mathrm{e}^{\prime}$ & 11 & (7) & 4 & (3) & 3 & (2) & 4 & (2) & & \\
\hline \multirow[t]{8}{*}{$I-2$} & a & 1 & $(0)$ & 0 & & 0 & & 1 & $(0)$ & \multirow{8}{*}{$1 \quad(0)$} & \\
\hline & $\mathrm{b}$ & 1 & (1) & 0 & & 0 & & 1 & (1) & & \\
\hline & $c$ & 31 & (5) & 10 & (2) & 13 & (2) & 7 & (0) & & \\
\hline & $d$ & 9 & (1) & 3 & $(0)$ & 4 & (1) & 2 & $(0)$ & & \\
\hline & $\mathrm{e}$ & 3 & (1) & 0 & & 1 & $(0)$ & 2 & (1) & & \\
\hline & f & 5 & (2) & 1 & $(0)$ & 2 & $(0)$ & 2 & (2) & & \\
\hline & $g$ & 17 & (3) & 4 & (1) & 3 & (1) & 10 & (1) & & \\
\hline & $\mathrm{h}$ & 7 & (3) & 2 & (1) & 3 & (1) & 2 & (1) & & \\
\hline \multirow[t]{3}{*}{ I-3 } & a & 12 & (2) & & $(0)$ & 2 & $(0)$ & & $(2)$ & \multirow{3}{*}{$1 \quad(0)$} & \\
\hline & b & 16 & (2) & 3 & (2) & 8 & $(0)$ & 5 & $(0)$ & & \\
\hline & $\mathrm{c}$ & 13 & (3) & 5 & (1) & 4 & (1) & 4 & (1) & & \\
\hline
\end{tabular}

( ): Number of cases with myocardial infarction.

The results are tabulated in Table $\mathrm{V}$. The $\mathrm{Q}$ wave in lead $\mathrm{aV} \mathrm{L}$, the item of I-1-c, was observed in 10 cases, in which 4 revealed myocardial infarction at autopsy, and 3 of 5 cases with persistent type showed myocardial infarction. The $Q$ wave in lead $\mathrm{aV}_{\mathrm{L}}$ with the duration of 0.03 to $0.04 \mathrm{sec}$. (I-2-c) were observed in 31 cases, in which only 5 cases of myocardial infarction were found. From this table, a high incidence of false positive cases can be seen in the I-2 and the I-3 classifications. QS patterns in leads II, III 
or $\mathrm{aV}_{\mathrm{F}}$ showed almost the same accuracy as the other sub-items in the I-1. It is worth noting that in 13 cases with the I-1-b sub-item, which included the $Q$ waves in lead $V_{1}$, myocardial infarction was confirmed in only 1 case at autopsy.

\section{Discussion}

In the present series, $20 \%$ of the total 697 consecutive autopsied cases of the aged revealed $Q$ and QS patterns classified according to the Minnesota code.

Ostrander and associates ${ }^{51}$ reported in the electrocardiographic survey in Tecumseh, Michigan, that the total classified $Q$ and QS patterns were observed in 55 cases or $8.3 \%$ among the 663 cases over the age of 60 , and the I- 1 was seen in 16 cases or $2.6 \%$, the I-2, in 17 cases or $2.6 \%$, and the $\mathrm{I}-3$, in 21 cases or $3.3 \%$. A rather high incidence of the classified $Q$ and $Q S$ patterns in our serics was partly due to the mcthod using serial electrocardiograms of the aged until death, and partly due to the source of the materials using hospitalized people including a different composition of sex and disease.

Although so called the Minnesota code was originally proposed for the purpose of population survey by Blackburn and associates, and not for clinicopathological study, it might be necessary to confirm at autopsy the degree of reliability of the classified $Q$ and QS patterns for the diagnosis of myocardial infarction. From the present results, the I-1 classification of the Minnesota code showed a relatively high reliability for the diagnosis of myocardial infarction in both sensitivity and specificity. The present results also indicate that it seems worthwhile to evaluate the QS pattern in leads II, III and $\mathrm{aV}_{\mathrm{F}}$, although the occurrence of these patterns in non-infarcted cases has been described by many authors. ${ }^{6)-8}$ ) On the other hand, it might be unnecessary to employ the lead $V_{1}$ for the criteria of I-1-b, because of the high occurrence of false positive diagnosis.

In this series, the abnormal $Q$ and $Q S$ patterns frequently appeared transiently or at the terminal stage of the aged in absence of myocardial infarction. A frequent appearance of the abnormal $Q$ waves that might be mistaken for myocardial infarction has been pointed out by a number of authors in the following conditions; myocardial lesions of obscure etiology ${ }^{9}$ including myocardial involvement in systemic disease such as amyloidosis, ${ }^{10}$ ) and others, ${ }^{11}$ acute pericarditis, ${ }^{12)}$ left ventricular hypertrophy and dilatation, ${ }^{13)}$ right ventricular hypertrophy and dilatation, ${ }^{14)}$ bundle branch block, ${ }^{15}$ W.P.W., ${ }^{16)}$ arrhythmia, ${ }^{17)}$ cor pulmonale, ${ }^{18)}$ pulmonary emphysema, ${ }^{19), 20)}$ electrolyte disturbance, ${ }^{21)}{ }^{22)}$ positional and respiratory changes of the electro- 
cardiographic patterns ${ }^{23)}$ and others. ${ }^{24), 25)}$ Extracardiac disorders, such as acute pancreatitis, acute cholecystitis, and intracranial lesions have been also proposed as a possible source of confusion in the electrocardiographic diagnosis of myocardial infarction, even if their real participation has not been determined.") Although a definite condition was not identified in the present materials, multiple factors described above might be involved in the appearance of these abnormal $Q$ waves, especially at the terminal stage of the aged in absence of infarction.

As pointed out by Simonson, ${ }^{2 /}$ the accuracy of these abnormal $Q$ and $Q S$ patterns for the diagnosis of myocardial infarction are related to the composition of infarcted cases in the studied materials. In the present materials, of which about 11 per cent were proved infarction at autopsy, a diagnostic accuracy of the I-1 classification for myocardial infarction was $45 \%$ at most. However, the persistent type of I-1 showed a much higher accuracy as $65 \%$. In the cases with $Q$ and $Q S$ patterns included in I-2 and I-3, on the other hand, the occurrence of false positive causes was about $86 \%$, indicating their low diagnostic accuracy. Even if recognition of abnormal $Q$ and $Q S$ patterns in electrocardiograms is not the only way to reach a correct clinical diagnosis of myocardial infarction, there are many cases with old myocardial infarction which show only $Q$ and QS patterns without any other clinical or electrocardiographic signs of infarction. The present results indicate that, if the diagnosis is based on only the abnormal $Q$ and QS patterns, the type of appearance of these findings as well as their classification might serve as an aid for a correct diagnosis of infarction of the aged. The combined recognition of the sub-items, of course, might elevate the diagnostic accuracy, although it was not analysed in this report.

\section{Summary}

(1) All available electrocardiograms of 697 cases of consecutive autopsies over the age of 60 , including 82 cases of myocardial infarction, were reviewed with respect to the $Q$ and QS patterns classified by the Minnesota code.

(2) Abnormal $Q$ and $Q S$ patterns meeting the criteria of the $I-1,-2$ and -3 classifications were observed in 143 cases or $20.5 \%$ of all 697 cases. These patterns appeared in 101 cases or $16.4 \%$ of the 615 cases without myocardial infarction, and in 42 cases or $51.2 \%$ of the 82 cases with myocardial infarction.

(3) The I-1 classification, especially of the persistent type, showed a high diagnostic reliability for myocardial infarction. The I-2 and the I-3, on the other hand, showed a low diagnostic accuracy regardless of the type of their 
appearance.

\section{AGKNOWLEDGment}

The authors wish to express their gratitude to Prof. Dr. Kiku Nakao, and to Dr. Fujiro Amako, for their helpful criticism and valuable suggestions.

\section{REFERENGES}

1. Kurihara, H., Kuramoto, K., Kurata, K., Terasawa, F., Seki, M., and Ikeda, M.: Jap. Heart $J$. in press.

2. Blackburn, H., Keys, A., Simonson, E., Rautaharju, P., and Punsar, S.: Circulation 21 : $1160,1960$.

3. Simonson, E. : Differentiation between normal and abnormal in electrocardiography. C. V. Mosby Co., St. Louis, 1961.

4. Pruitt, R. D., Dennis, E. W., and Kinard, S. A.: Progr. Cardiovasc. Dis. 6: 85, 1963.

5. Ostrander, L. D. Jr., Brandt, R. L., Kjelsberg, M. O., and Epstein, F. H. : Circulation 31 : $888,1965$.

6. Ferrero, C., Doret, J., and Gay, E. : Cardiologia 20: 47, 1952.

7. Burch, G. E., Abildskov, J. A., and Cronvich, J. A. : Circulation 9 : 381, 1954.

8. Pearce, M. L. and Chapman, M. G. : Am. Heart J. 53 : 782, 1957.

9. Pruitt, R. D., Curd, G. W., and Leachman, R. D.: Circulation 25 : 506, 1962.

10. Josselson, A. J. and Pruitt, R. D. : Circulation 7: 200, 1953.

11. Gilroy, J., Cahalan, J. L., Berman, R., and Newman, M.: Circulation 27 : 484, 1963.

12. Bullington, R. H. and Bullington, J. D. : J.A.M.A. 171 : 2205, 1959.

13. Myers, G. B.: Girculation 1 : 844, 1950.

14. Myers, G. B. : Circulation 1: 860, 1950.

15. Myers, G. B.: Girculation 2:60, 1950.

16. Wasserburger, R. H., White, D. H., and Lindsay, E. R. : Am. Heart J. 64 : 617, 1962.

17. Rubin, I. L., Gross, H., and Arbeit, S. R. : Am. J. Cardiol. 11: 659, 1963.

18. Wolf, L.: Circulation 6: 768, 1952.

19. Bernreiter, M.: Dis. Chest 37: 573, 1960.

20. Murata, K., Hashiba, K., Ikeda, M., and Seki, M.: Jap. Girculat. J. 27 : 359, 1963.

21. Myers, G. B.: Circulation 2: $75: 1950$.

22. Nora, T. R. and Pilz, C. G. : Arch. Int. Med. 104: 300, 1959.

23. August, T., Mazzelni, A., and Wolff, L.: Am. Heart J. 55 : 706, 1959.

24. Sodi-Pallares, D., Bisteni, A., and Herrmann, G. R. : Am. Heart J. 43 : 716, 1952.

25. Goldman, A. G., Gross, H., and Rubin, I. L. : Am. Heart J. 60:61, 1961. 